\title{
Excellent toluene removal via adsorption by honeycomb adsorbents under high temperature and humidity conditions
}

\author{
Min-Whee Cho ${ }^{1}$, Jongjin Kim¹, Jeong Min Jeong', Bongbeen Yim ${ }^{1 \dagger}$, Hyun-Jae Lee ${ }^{1}$, Yoonjong Yoo ${ }^{2}$ \\ 1 enbion Inc., Daejeon 34026, Republic of Korea \\ ${ }^{2}$ Korea Institute of Energy Research, Daejeon 34129, Republic of Korea
}

\begin{abstract}
Removal through adsorption is the most widely used and effective treatment method for volatile organic compounds (VOCs) in exhaust gases. However, at high temperatures and humidity, adsorption is competitive due to the presence of moisture and unsmooth physical adsorption thereby deteriorating adsorption performance. Therefore, water adsorption honeycomb (WAH) and VOCs adsorption honeycomb (VAH) were prepared to improve VOCs adsorption at high temperatures and humidity. Adsorbed toluene amounts on single honeycomb ( $\mathrm{SH}$ ), containing only $\mathrm{VAH}$, and combined honeycomb $(\mathrm{CH})$, containing $\mathrm{WAH}$ and $\mathrm{VAH}$, were determined. Further, the toluene adsorption rates of honeycomb adsorbents mounted on rotary systems, $\mathrm{VAH}$-single rotor (SR) and WAH/VAH-dual rotor (DR) were determined. Toluene adsorption by WAH/VAH-CH (inlet temperature: $40-50^{\circ} \mathrm{C}$; absolute humidity: $28-83 \mathrm{gH}_{2} \mathrm{O} / \mathrm{kg}$-dry air) was 1.6 times that by $\mathrm{VAH}-\mathrm{SH}$, and the water adsorption efficiency of $\mathrm{WAH} / \mathrm{VAH}-\mathrm{CH}$ was 1.7 times that of $\mathrm{VAH}-\mathrm{SH}$. The adsorption/removal efficiency of the WAH/VAH-DR (inlet temperature: $45^{\circ} \mathrm{C}$; absolute humidity: $37.5 \mathrm{gH}_{2} \mathrm{O} / \mathrm{kg}$-dry air) was $3 \%$ higher than that of $\mathrm{VAH}-\mathrm{SR}$. This indicates that the WAH at the rotor inlet selectively removed water, thereby improving the adsorption efficiency of the VAH at the outlet.
\end{abstract}

Keywords: Adsorption/desorption, Honeycomb adsorbents, Rotary adsorption systems, Volatile organic compounds, ZSM-5 zeolite

\section{Introduction}

Various volatile organic compounds (VOCs) are emitted during the manufacture and storage of organic solvents, paints, coating materials, and petrochemical products [1]. These compounds are harmful for human health and combine with nitrogen oxides in the atmosphere, causing secondary air pollution such as photochemical smog [2]. Emissions of VOCs are becoming a global concern, and many countries are making great efforts to reduce them.

Treatment methods for VOCs can be broadly divided into collection and removal processes [3]. Regeneration processes include distillation, adsorption, and absorption, while thermal incineration, catalytic incineration, and catalytic oxidation are used for the removal of VOCs. Adsorption is advantageous for energy saving as it allows collection or recycling of organic solvents generated in industrial processes [3, 4].

The use of an adsorption tower filled with granular adsorbents is a typical adsorption method [5]. However, large pressure losses occur in fixed adsorption towers filled with granular adsorbents, and therefore a separate pressurizing device is required to process exhaust gases [6]. In recent years, rotary adsorption systems that can adsorb and regenerate VOCs while reducing pressure load through the use of a honeycomb-like structure coated with adsorbent materials has been widely applied, and studies on such systems are being actively conducted [7-9]. Such adsorption systems have a simple configuration and minimize installation scale as they require only one adsorption rotor, which can be used for several adsorption and regeneration cycles [10, 11].

The adsorption performance of an adsorbent depends on its structure, type, and composition. Activated carbon and zeolite are the most widely used adsorbents [12, 13]. In recent years, zeolite has become more popular than activated carbon due to its high regeneration ability. Zeolite can be either hydrophilic or hydrophobic depending on its silica and alumina molar ratios. Hydrophobic zeolite can be used under high moisture conditions, as it will selectively adsorb the target compound while repelling water [14-16]. However, the ratio of high and low silica zeolite needs to be optimized to adsorption conditions because high humid-
This is an Open Access article distributed under the terms of the Creative Commons Attribution Non-Commercial License (http://creativecommons.org/licenses/by-nc/3.0/) which permits unrestricted non-commercial use, distribution, and reproduction in any medium, provided the original work is properly cited.

Copyright (C) 2020 Korean Society of Environmental Engineers
Received December 21, 2018 Accepted March 1, 2019

${ }^{\dagger}$ Corresponding author

Email: yim@enbion.co.kr

Tel: +82-42-863-8675 Fax: +82-42-863-8677

ORCID: 0000-0003-2012-8602 
ity deteriorates its absorptivity. Further, zeolite is sensitive to moisture present in the atmosphere and temperature [12, 17]. The effects on adsorption by differences in physicochemical properties between the adsorbent and the adsorbate and the competitive adsorption of between moisture and VOCs had been reported [14, 18]. Moreover, it is difficult to remove VOCs under high temperature and humidity conditions. In order to solve these problems, we developed a rotor system with a dual adsorption system for removing simultaneously VOCs under high temperature and humidity conditions.

In this study, a water adsorption honeycomb (WAH) and VOC adsorption honeycomb (VAH) were prepared. Further, a single honeycomb (SH) composed of only VAH and a combined honeycomb (CH) with both WAH and VAH were fabricated. A VAH-single rotor (SR) and WAH/VAH-DR, which were mounted on a rotary system, were developed. Subsequently, the VAH-SH and WAH/VAH-CH were attached to a continuous adsorption/desorption device. The amount of toluene adsorbed was then evaluated under varying inlet temperatures and absolute humidity. Finally, the toluene removal efficiencies of VAH-SR and WAH/VAH-DR were compared under high temperature and humidity conditions.

\section{Experimental Methods}

\subsection{Preparation of Adsorption Honeycomb}

Fine silica powder (SS-230, Particle Size: $3.5 \mu \mathrm{m}$, Schemtech) was used for the fabrication of the WAH. This powder was dispersed in a $3 \%$ solution of silica sol (YGS-30, Young Il Chemical), which is an inorganic binder. A glass fiber honeycomb was dipped in this mixture, dried at $100^{\circ} \mathrm{C}$ for $12 \mathrm{~h}$, and then calcined at $300^{\circ} \mathrm{C}$ for $2 \mathrm{~h}$ to prepare the WAH. ZSM-5 zeolite $\left(\mathrm{SiO}_{2} / \mathrm{Al}_{2} \mathrm{O}_{3}\right.$ molar ratio $>100$, UOP) powder was used as the adsorbent for the VAH. A ceramic honeycomb was dipped in a $10 \%$ silica sol solution containing dispersed zeolite, dried at $100^{\circ} \mathrm{C}$ for $12 \mathrm{~h}$, and then calcined at $500^{\circ} \mathrm{C}$ for $6 \mathrm{~h}$ to prepare the $\mathrm{VAH}$.

The fabricated WAH and VAH was cut cylinders measuring $100 \mathrm{~mm}$ in diameter, 100 and $300 \mathrm{~mm}$ in length to prepare the WAH-SH and VAH-SH, respectively. The fabricated WAH and VAH were combined in a length ratio of $1: 3(\mathrm{v} / \mathrm{v})$ at the adsorption honeycomb and then cut into cylinders measuring $100 \mathrm{~mm}$ in diameter and $400 \mathrm{~mm}$ in total length to prepare the WAH/VAH-CH. Further, WAH-SR and VAH-SR with dimensions of $500 \mathrm{~mm}$ (diameter), 200 and $400 \mathrm{~mm}$ (length) was used to confirm the adsorption/removal efficiency. The WAH/VAH-DR, measuring $500 \mathrm{~mm}$ in diameter and $600 \mathrm{~mm}$ in total length, was fabricated by combining the desiccant and adsorbent in a ratio of 1:2 (v/v).

\subsection{Fixed Bed Continuous Adsorption/Desorption Device}

Adsorption experiments with the VAH-SH and WAH/VAH-CH were carried out using a fixed-bed continuous adsorption/desorption device as shown in Fig. 1. The experimental apparatus consisted of an adsorbate generation module, adsorbent filling module, and analysis module. Toluene was injected into the adsorbent generation module at a constant concentration of 100 ppm using a mass flow controller. Further, a blower was used to maintain the gas hourly space velocity (GHSV) at 20,000 /h. The absolute humidity was

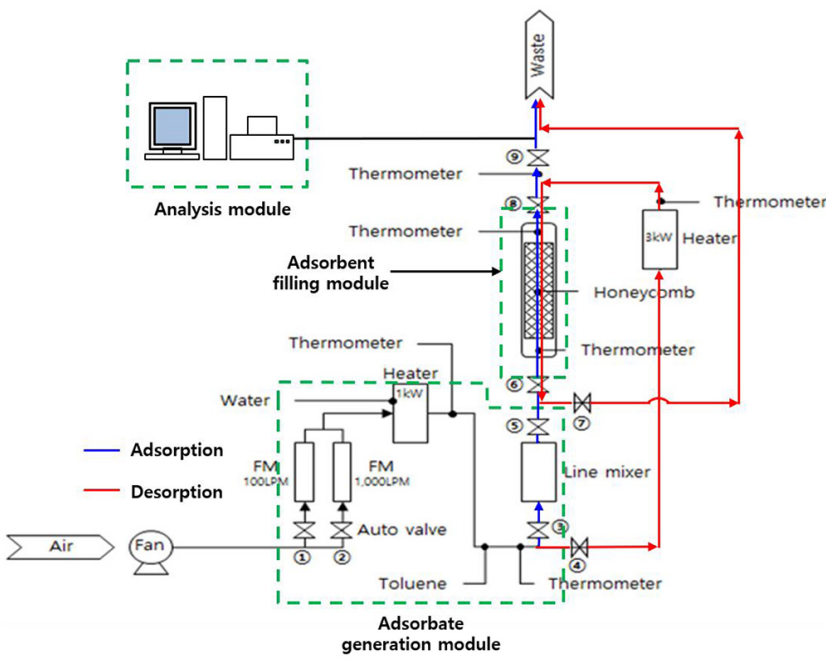

Fig. 1. Schematic diagram of the sequential reactor used for adsorption/desorption. $\mathrm{VAH}-\mathrm{SH}$ and $\mathrm{WAH} / \mathrm{VAH}-\mathrm{CH}$ were filled inside the adsorbent filling module.

maintained at 28-83 $\mathrm{gH}_{2} \mathrm{O} / \mathrm{kg}$-dry air using an aluminum heating block $(250 \times 200 \times 20 \mathrm{~mm}, 3 \mathrm{~kW}$, Solution Eng. $)$ and a liquid pump (HPLH PF 200, CAT, Germany) depending on the required experimental conditions. In the adsorbent filling module, VAH-SH and WAH/VAH-CH (diameter: $100 \mathrm{~mm}$; length: $400 \mathrm{~mm}$ ) were filled inside a stainless-steel cylindrical reactor with an inner diameter of $105 \mathrm{~mm}$ and a length of $410 \mathrm{~mm}$. Subsequently, the amounts of water and toluene adsorbed were confirmed. During adsorption, No. 2, 3, 5, 6, 8, and 9 valves were opened, and the inlet temperature was kept constant. During desorption, No. 1, 4, 8, and 6 valves were opened and a constant temperature was maintained.

The temperature and humidity in the inlet and outlet of adsorber were measured using a temperature/humidity sensor (SK-L200TH, SATO, Japan). Toluene concentration was determined using a total hydrocarbon analyzer (51i, Thermo, USA) equipped with a flame ionization detector.

To calculate the saturated adsorption capacity of the adsorbent, amount of adsorbate per unit adsorbent, and breakthrough adsorption time, toluene and air containing moisture were injected into the reactor at a constant concentration. Toluene concentration was measured by considering that adsorption equilibrium was attained when the toluene concentration at the outlet of the adsorber before and after adsorption was almost equal to the toluene concentration at the inlet.

The breakthrough curve is expressed as the ratio $\left(C_{0} / C_{i}\right)$ of outflow concentration $\left(C_{0}\right)$ to inflow concentration $\left(C_{i}\right)$ according to the adsorption time $(t)$. The outflow concentration is measured at the outlet of the adsorption reactor with respect to time. The adsorption amount refers to the saturated adsorbate amount adsorbed and can be calculated using Eq. (1) [13].

$$
q=\frac{1}{W} C_{i} Q\left(t_{T}-\frac{1}{C_{i}} \int_{0}^{t} C_{o} d t\right)
$$

where $q$ is the equilibrium adsorption amount (mg/g), $C_{i}$ is the adsorbate concentration (ppm) at the inlet of the adsorption layer, $C_{o}$ is ppm at the outlet of the adsorption layer, $W$ is the adsorbent 
filling amount (g), $Q$ is the inflow rate $(\mathrm{L} / \mathrm{min})$ of the adsorbate gas, and $t_{T}$ is the time (min) at which the adsorbent reaches saturation.

\subsection{Rotary Adsorption System}

After determining the saturated adsorption capacities of VAH-SH and WAH/VAH-CH, a rotary system was introduced to fabricate the VAH-SR and WAH/VAH-DR. VAH-SR and WAH/VAH-DR were mounted on a rotary adsorption system, as shown in Fig. 2, and the corresponding VOC removal efficiencies of the rotary concentrator adsorption systems were evaluated. As shown in Fig. 2, the honeycomb rotor was divided into adsorption, desorption, and cooling zones (8:1:1 ratio) by the external equipment. The adsorption/removal rate of the honeycomb rotor (rotating at $3 \mathrm{RPH}$ (revolutions per hour)) was measured. The zone in which complete adsorption was achieved at room temperature (about $20^{\circ} \mathrm{C}$ ) was transferred to the desorption zone, so that the adsorbed adsorbate can be desorbed and regenerated by the regeneration air, which is maintained at $220^{\circ} \mathrm{C}$. The desorption zone was moved to the cooling zone, where the temperature was reduced to $50^{\circ} \mathrm{C}$ (or lower) by some

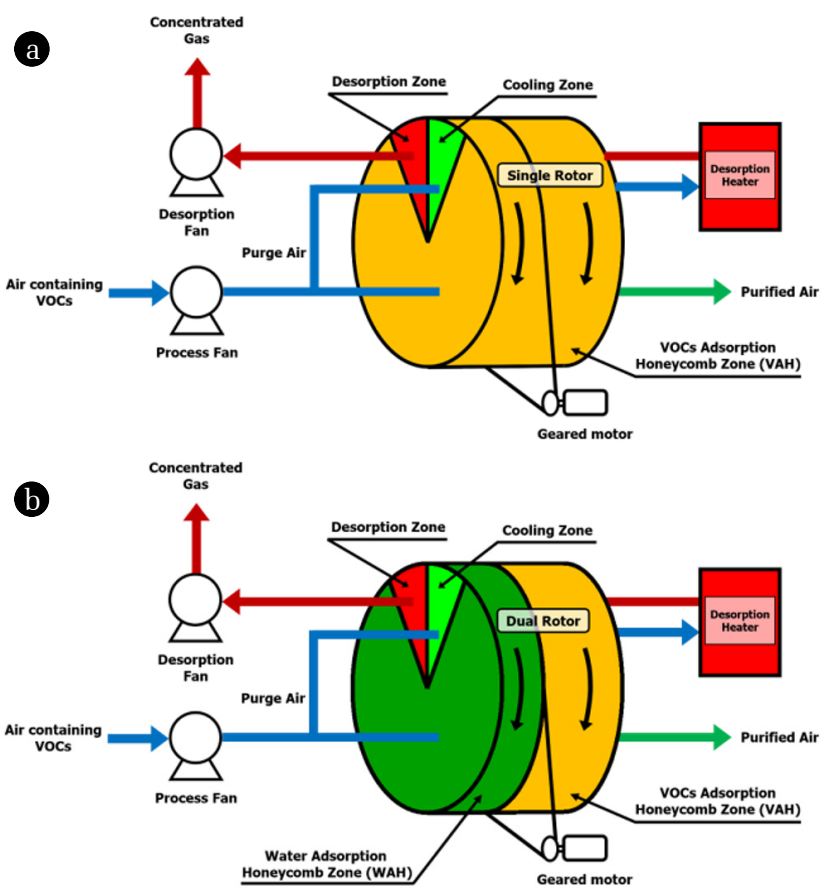

Fig. 2. Schematic diagram of the rotary honeycomb adsorption system (a: VAH-SR, b: WAH/VAH-DR) used for VOC removal.

outside air entering the adsorption region so as to facilitate VOCs adsorption. Sequentially, the VOCs in the incoming gas were removed via adsorption on the regenerated honeycomb adsorbent. Toluene removal efficiency can be calculated using Eq. (2).

$$
\begin{aligned}
& \text { Removal efficiency }(\%)= \\
& \qquad\left(1-\frac{\text { Toluene concentration after adsorption }}{\text { Toluene concentration before adsorption }}\right) \times 100
\end{aligned}
$$

\subsection{Characterization of the Honeycomb Adsorbents}

The shape, size, and distribution of particles on the surface of the WAH and VAH, fabricated in this study, were analyzed via scanning electron microscopy (SEM, TESCAN, Mira 3 LMV FEG, Czech). To determine the pore characteristics of the adsorbent, Brunauer-Emmett-Teller (BET) specific surface area $\left(S_{B E T}\right)$, total pore volume $\left(V_{T}\right)$, and average pore diameter $(D p)$ were measured using a BET surface area analyzer (Micromeritics, ASAP2010, USA).

\section{Results and Discussion}

\subsection{Physical Properties of Adsorbent}

Fig. 3 shows the SEM images of WAH-SH (Fig. 3(a-1), (a-2)) containing fine silica powder and VAH-SH (Fig. 3(b-1), (b-2)) containing zeolite. SEM images of the surface of the WAH-SH, which is coated with fine silica powder, showed a uniform distribution of fine microcrystalline silica powder on the glass fiber surface (Fig. 3(a-2)). SEM images (VAH-SH) of the ceramic sheet surface coated with zeolite, ceramic fibers formed a grain-like structure and zeolite particles were uniformly distributed (Fig. 3(b-2)). Table 1 shows the surface area, pore volume, and $D p$ of fine silica powder and zeolite used as adsorbent materials, and zeolite-coated honeycomb adsorbent. The $S_{B E T}$ of the fine silica powder $\left(287.6 \mathrm{~m}^{2} / \mathrm{g}\right)$ was smaller than that of the ZSM-5 zeolite $\left(410 \mathrm{~m}^{2} / \mathrm{g}\right)$ by $122.4 \mathrm{~m}^{2} / \mathrm{g}$. However, $V_{T}$ (total pore volume) of fine silica powder was 7 times greater than that of the ZSM-5 zeolite powder, while its Dp was about 5.5 times larger than that of ZSM-5 zeolite. This may be attributable to the pores formed by the aggregation of non-crystalline fine silica particles. In addition, the specific surface area of the ZSM-5 zeolite powder was significantly reduced from $410 \mathrm{~m}^{2} / \mathrm{g}$ prior to coating to $152 \mathrm{~m}^{2} / \mathrm{g}$ after coating on the ceramic honeycomb. Some of the silica sol particles used as binder during coating may have been dispersed into the zeolite pores, thereby decreasing the surface area.

\begin{tabular}{|c|c|c|c|}
\hline Sample & $\mathrm{S}_{\mathrm{BET}}\left(\mathrm{m}^{2} / \mathrm{g}\right)$ & $V_{\text {total }}\left(\mathbf{c m}^{3} / \mathbf{g}\right)^{\mathrm{a}}$ & $\mathrm{Dp}(\mathrm{nm})^{\mathrm{b}}$ \\
\hline Silica powder (SS230) & 287.6 & 1.40 & 16.8 \\
\hline Parent ZSM-5 zeolite powder & 410 & 0.20 & 2.9 \\
\hline ZSM-5 zeolite-coated honeycomb & 152 & 0.19 & 7.0 \\
\hline Silica-coated glass fiber honeycomb & 414.5 & 0.41 & 3.9 \\
\hline
\end{tabular}

Table 1. Physical Properties of ZSM-5, Fine Silica Powder, ZSM-5 Coated Honeycomb, and Silica-Coated Glass Fiber Honeycomb

a Total pore volume evaluated at $\mathrm{P} / \mathrm{P}_{0}=0.99$.

${ }^{\mathrm{b}} \mathrm{BJH}$ adsorption average pore diameter. 

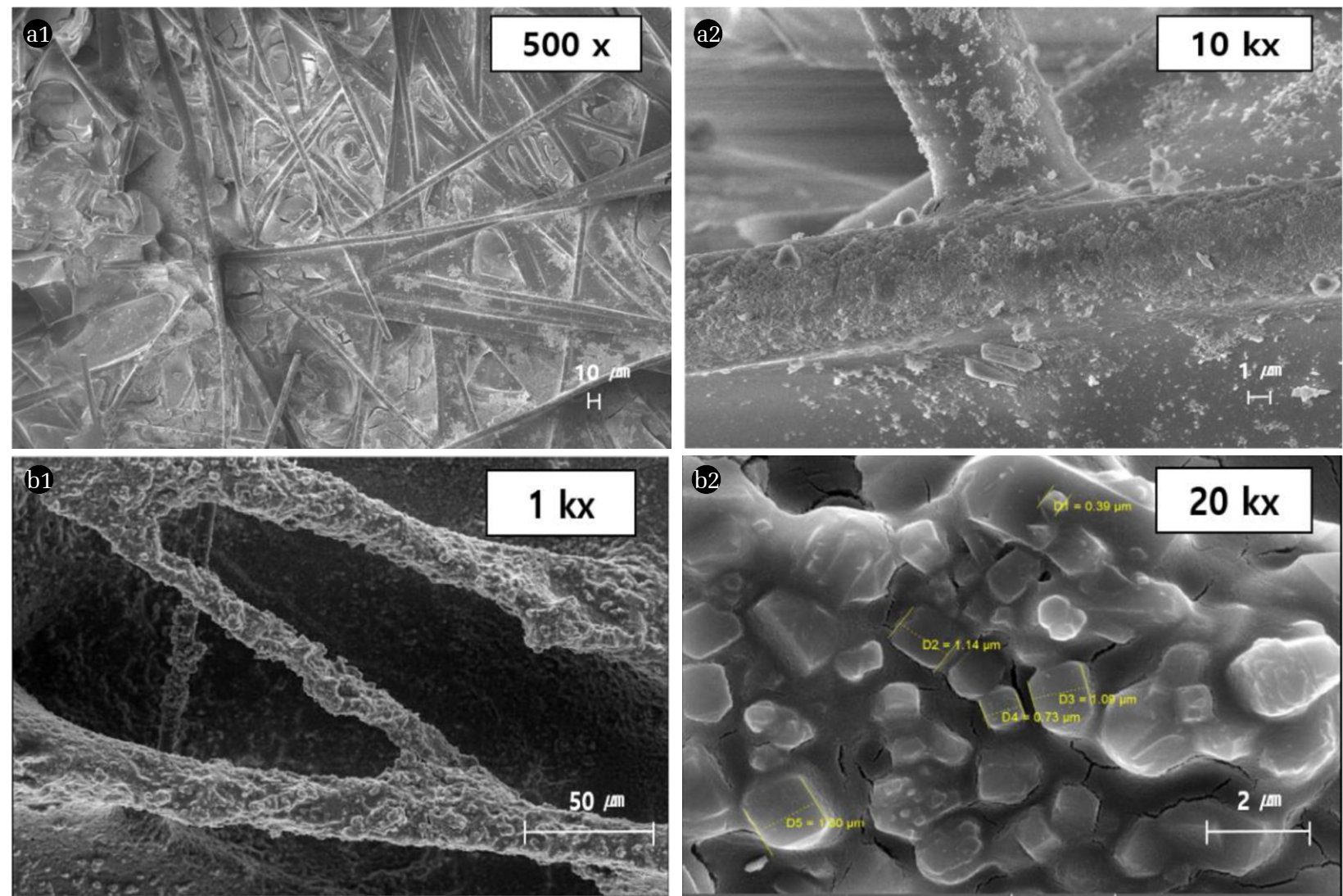

Fig. 3. SEM images of WAH-SH (a1, a2) as fine silica powder-coated honeycomb adsorbent and VAH-SH (b1, b2) as zeolite-coated honeycomb adsorbent.

\subsection{Water Adsorption Amount}

To estimate the influence of relative humidity on the water adsorption capacity of WAH-SH, the absolute humidity (relative humidity) was set at $12.9 \mathrm{gH}_{2} \mathrm{O} / \mathrm{kg}$-dry air (15\%) and $49.1 \mathrm{gH}_{2} \mathrm{O} / \mathrm{kg}$-dry air (60\%). Water was continuously adsorbed at an inlet temperature of $50^{\circ} \mathrm{C}$ and a gas flow rate of $1 \mathrm{NCMM}$ (normal cubic meter per min). The water absorption amounts calculated using Eq. (3) is shown in Table 2.

Water adsorption amount =

(Adsorption weight after adsorption - Adsorption weight before adsorption)

$$
\text { Adsorption weight before adsorption }
$$

The water adsorption amount by WAH-SH at absolute humidity (relative humidity) of $12.9 \mathrm{gH}_{2} \mathrm{O} / \mathrm{kg}$-dry air (15\%) and 49.1 $\mathrm{gH}_{2} \mathrm{O} / \mathrm{kg}$-dry air (60\%) was $20 \mathrm{mg} / \mathrm{g}$ and $118 \mathrm{mg} / \mathrm{g}$, respectively.
Yang et al. [19] reported that silica has excellent water adsorption performance, and that its water adsorption capacity increases proportionally with increase in relative humidity. Therefore, WAH is considered to have a sufficiently high water adsorption capacity at the absolute humidity levels considered in this study.

\subsection{Toluene Adsorption Amount}

Fig. 4(a) shows the toluene adsorption capacity of VAH-SH as a function of temperature. Input gas temperatures of 40, 50, and $60^{\circ} \mathrm{C}$, absolute humidity of $28.5 \mathrm{gH}_{2} \mathrm{O} / \mathrm{kg}$-dry air, initial toluene concentration of $100 \mathrm{ppm}$, and GHSV of 20,000/h were considered in this study. Adsorption was carried out continuously to measure the toluene adsorption amount. Toluene adsorption amounts were 28.66, 23.36, and $21.37 \mathrm{mg} / \mathrm{g}$ at input gas temperatures of 40, 50, and $60^{\circ} \mathrm{C}$, respectively. Absorption efficiency decreased with increase in temperature because the absorptivity of an adsorbent is inversely proportional to temperature as physical adsorption

Table 2. Water Adsorption Amount as a Function of Relative Humidity

\begin{tabular}{lcccccc}
\hline \multirow{2}{*}{ Honeycomb support } & Coating material & $\begin{array}{c}\text { Relative humidity } \\
\text { (RH, \%) }\end{array}$ & \multicolumn{3}{c}{ Adsorbent weight (g) } & \multicolumn{2}{c}{$\begin{array}{c}\text { Water adsorption } \\
\text { amount (mg/g) }\end{array}$} \\
\cline { 3 - 6 } Glass fiber & \multirow{2}{*}{ Silica powder } & 15 & 817 & 833 & 20 \\
\cline { 3 - 6 } & & 60 & 1,060 & 1,185 & 118 \\
\hline
\end{tabular}



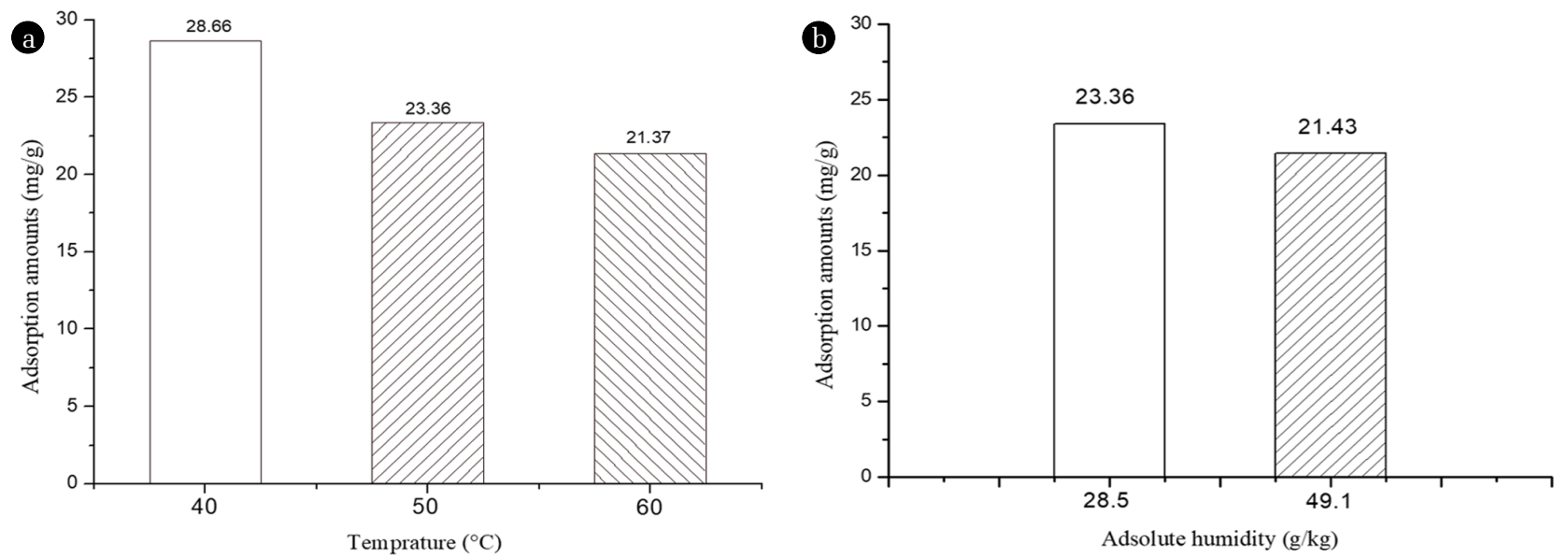

Fig. 4. a) Toluene adsorption amount as a function of input gas temperature (toluene concentration: 100 ppm; absolute humidity: 28.5 gH $\mathrm{H}_{2} \mathrm{O} / \mathrm{kg}^{-} \mathrm{dry}$ air; GHSV: 20,000/h; input gas temperature: 40, 50, and $60^{\circ} \mathrm{C}$ ). b) Toluene adsorption amount as a function of input gas absolute humidity (toluene concentration: $100 \mathrm{ppm}$; absolute humidity: 28.5 and $49.1 \mathrm{gH}_{2} \mathrm{O} / \mathrm{kg}$-dry air; GHSV: 20,000/h; input gas temperature: $50^{\circ} \mathrm{C}$ ).

involves Van der Waals interactions [20].

The influence of absolute humidity on toluene adsorption amount by VAH-SH was determined. Absolute humidity of 28.5 and $49.1 \mathrm{gH}_{2} \mathrm{O} / \mathrm{kg}$-dry air, inlet temperature of $50^{\circ} \mathrm{C}$, toluene concentration of $100 \mathrm{ppm}$, and GHSV of 20,000/h were used for this purpose. Subsequently, continuous toluene adsorption was carried out, the results of which are shown in Fig. 4(b). At absolute humidity of 28.5 and $49.1 \mathrm{gH}_{2} \mathrm{O} / \mathrm{kg}$-dry air, toluene adsorption amounts were 23.36 and $21.43 \mathrm{mg} / \mathrm{g}$, respectively. A mixture of two or more types of substances (such as a mixture of toluene and water) causes competitive adsorption by VAH-SH. The moisture present in mixtures with high humidity may have diffused into the pores of VAH, thereby decreasing its toluene adsorption capacity. Therefore, under conditions above $49.1 \mathrm{gH}_{2} \mathrm{O} / \mathrm{kg}$-dry air $(60 \% \mathrm{RH})$ absolute humidity, toluene adsorption performance of the adsorbent would be decreased [21].

Based on the abovementioned results, adsorption experiments

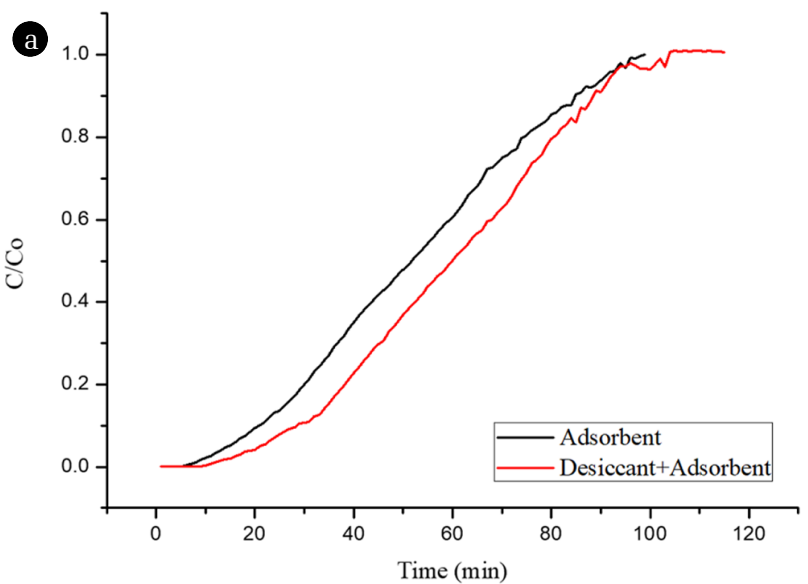

were carried out under high temperature and humidity conditions at an input gas temperature of $50^{\circ} \mathrm{C}$ and absolute humidity of 49.1 $\mathrm{gH}_{2} \mathrm{O} / \mathrm{kg}$-dry air. Subsequently, desorption was carried out five times at a temperature of $200^{\circ} \mathrm{C}$ and desorption gas flow rate of 0.2 NCMM to determine the durability of VAH. The average toluene adsorption amount was $20.53 \pm 0.18 \mathrm{mg} / \mathrm{g}$. The adsorption performance of the adsorbent was maintained without inactivation even after five cycles of toluene adsorption/desorption.

\subsection{Comparison of the $\mathrm{SH}$ and $\mathrm{CH}$ Adsorbents}

The adsorption performance of WAH/VAH-CH (adsorbent:desiccant ratio of 3:1) was evaluated at an input gas temperature of $50^{\circ} \mathrm{C}$, absolute humidity (relative humidity) of 49.1 $\mathrm{gH}_{2} \mathrm{O} / \mathrm{kg}$-dry air $(60 \%)$, and toluene concentration of $100 \mathrm{ppm}$ (Fig. 5(a)). The adsorption amount refers to the saturated adsorbate amount adsorbed and can be calculated using Eq. (1).

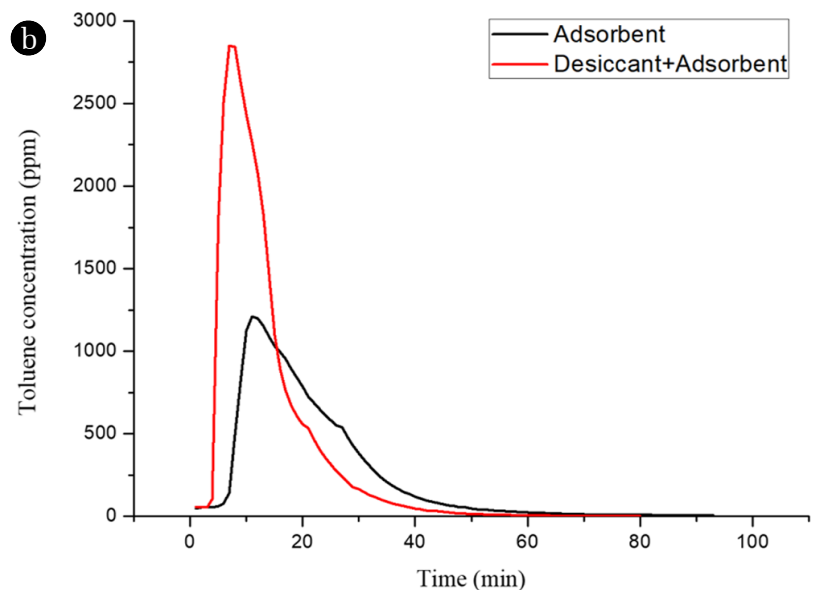

Fig. 5. a) Comparison of the adsorption curves of the single and combined absorbent systems. (toluene concentration: 100 ppm; GHSV: 20,000 /h; absolute humidity: $49.1 \mathrm{gH}_{2} \mathrm{O} / \mathrm{kg}$-dry air; input gas temperature: $50^{\circ} \mathrm{C}$ ). b) Comparison of the desorption curves of the single and combined absorbent systems. (inlet temperature: $200^{\circ} \mathrm{C}$; gas flow rate: $0.2 \mathrm{NCMM}$ ). 
Table 3. Water Adsorption Amount and Toluene Removal Efficiency of the Single and Dual Honeycomb Rotor System

\begin{tabular}{|c|c|c|c|c|c|c|}
\hline Rotor & \multicolumn{3}{|c|}{ Single honeycomb rotor } & \multicolumn{3}{|c|}{ Dual honeycomb rotor } \\
\hline Water content according to the measurement & Inlet & Outlet & Difference & Inlet & Outlet & Difference \\
\hline position ( $\mathrm{gH}_{2} \mathrm{O} / \mathrm{kg}$-dry air) & 40.8 & 34.5 & 6.3 & 40.8 & 29.8 & 11 \\
\hline Water adsorption amount $\left(\mathrm{m}^{3}\right)$ & & 80.7 & & & 93.0 & \\
\hline Toluene removal efficiency (\%) & & $\begin{array}{l}94.7^{\mathrm{a}} \\
88.4^{\mathrm{b}}\end{array}$ & & & $\begin{array}{l}95.7^{\mathrm{a}} \\
91.1^{\mathrm{b}}\end{array}$ & \\
\hline
\end{tabular}

${ }^{\mathrm{a}}$ Number concentration is 6.6

${ }^{\mathrm{b}}$ Number concentration is 10

Toluene adsorption amount by VAH-SH was $21.34 \mathrm{mg} / \mathrm{g}$, while that by WAH/VAH-CH was $34.29 \mathrm{mg} / \mathrm{g}$, of which toluene adsorption by WAH was $0.45 \mathrm{mg} / \mathrm{g}$. Toluene gas with high moisture contents may have passed through the WAH/VAH-CH, and the moisture may have been primarily adsorbed by the WAH, thereby lowering the moisture content of the gas. Thus, the selectivity of VAH for toluene was improved, and the toluene adsorption amount by WAH/VAH-CH was above $12.5 \mathrm{mg} / \mathrm{g}$ more than VAH-SH [21].

Fig. 5(b) shows the desorption of adsorbate from WAH/VAH-CH and VAH-SH at an inlet temperature of $200^{\circ} \mathrm{C}$ and gas flow rate of 0.2 NCMM. Desorption from WAH/VAH-CH began at $5 \mathrm{~min}$, and maximum toluene desorption (2,700 ppm) was achieved within $10 \mathrm{~min}$. In the case of VAH-SH, desorption began at $8 \mathrm{~min}$, the concentration of toluene desorbed after $11 \mathrm{~min}$ was 1,200 ppm, and tailing of the desorption curve was observed. The water adsorption amount by VAH-SH was higher than that by WAH/VAH-CH. This is because in the case of VAH-SH, desorption energy was used to desorb water besides toluene, thereby increasing desorption time [21].

\subsection{Evaluation of Water and Toluene Adsorption using the Honeycomb Rotor System}

Table 3 shows the water adsorption amount and toluene removal efficiency of the VAH-SR and WAH/VAH-DR. The water contents at the inlet and outlet of the honeycomb rotor system maintained at a temperature of $40^{\circ} \mathrm{C}$ and an absolute humidity (relative humidity) of $36 \mathrm{gH}_{2} \mathrm{O} / \mathrm{kg}$-dry air (80\%) were measured to determine water adsorption amount. The moisture content at the inlet of VAH-SR was $40.8 \mathrm{gH}_{2} \mathrm{O} / \mathrm{kg}$-dry air, while that at its outlet was 34.5 $\mathrm{gH}_{2} \mathrm{O} / \mathrm{kg}$-dry air, which is a decrease in moisture content of approximately $6.3 \mathrm{gH}_{2} \mathrm{O} / \mathrm{kg}$-dry air. At the outlet of the WAH/VAH-DR, water content was $29.8 \mathrm{gH}_{2} \mathrm{O} / \mathrm{kg}$-dry air, which is less than that at its inlet by about $11.0 \mathrm{gH}_{2} \mathrm{O} / \mathrm{kg}$-dry air. This indicates that the water removal capacity of WAH/VAH-DR is approximately 1.7 times that of VAH-SR. Water adsorption amount was determined as a function of the total honeycomb volume. It was observed that water adsorption amount per unit volume of VAH-SR was $80.7 \mathrm{~g} / \mathrm{m}^{3}$, while that per unit volume of WAH/VAH-DR was 93.0 $\mathrm{g} / \mathrm{m}^{3}$. This means that amount of water adsorbed per unit volume of WAH/VAH-DR is 1.15 times that per unit volume of VAH-SR. This is because the WAH present at the inlet may have adsorbed relatively more water.

For evaluation of the toluene removal efficiency, the desorption flow rate was set at 2 and 3 NCMM. Conditions were temperature of $45^{\circ} \mathrm{C}$, absolute humidity (relative humidity) of $37.5 \mathrm{gH}_{2} \mathrm{O}$ / kg-dry air (60), toluene concentration of $100 \mathrm{ppm}$, and adsorption gas flow rate of 20 NCMM. The toluene adsorption efficiency of both types of rotors decreased with increase in number concentration. However, the decrease in the adsorption efficiency of the DR was smaller than that of the SR. Thus, the high toluene removal rate of the DR system may be attributable to the adsorption of water by the WAH present at the inlet of the DR system [21].

\section{Conclusions}

In this study, WAH/VAH-CH was prepared and evaluated on a fixed bed continuous adsorption/desorption system. WAH/VAH-DR was used for the evaluation by mounting WAH/VAH-CH on a rotary system. Toluene adsorption efficiencies were evaluated at high temperature and humidity conditions (inlet temperature of $40-50^{\circ} \mathrm{C}$ and absolute humidity of $28-83 \mathrm{gH}_{2} \mathrm{O} / \mathrm{kg}$-dry air). The toluene adsorption amount decreased with increase in temperature and humidity. It was difficult to achieve high absorptivity with only VAH under high temperature and humidity conditions due to decreased Van der Waals interactions caused by increased temperature and competitive adsorption of two or more types of substances. WAH/VAH-CH and WAH/VAH-DR, which are composed of two adsorbent layers, were produced to improve VOC adsorption performance under high temperature and humidity conditions. Toluene and water adsorption amount by WAH/VAH-CH were 1.6 and 1.7 times, respectively, those of VAH-SH. Further, the toluene removal efficiency of WAH/VAH-DR was 3\% higher than that of VAH-SR. The WAH at the rotor inlet may have primarily and selectively adsorbed water, thereby improving the adsorption performance of the VAH located at the rotor outlet. However, we have not identified the adsorption tendency and efficiency of the various VOCs in this study. Therefore, further studies for improving the efficiency of dehumidification and VOCs adsorption using the dual rotary adsorption system under various conditions (e.g., number of revolutions, types and concentrations of VOCs, composition ratio of desiccant and VOCs adsorbent, etc.) would be performed. It seems likely that the dual rotary adsorption system suggested by this study suitable for the air pollution control technology for a variety of VOCs emissions sources, if the results of this study are successful to design by determining the suitable operation conditions. 


\section{Acknowledgments}

This subject is supported by Korea Ministry of Environment (MOE) as "Advancement of Environmental Industry Technology Development Program for Environmental Technology (No. 2016000110001)".

\section{References}

1. Noordally E, Richmond JR, Drumm KJ. Catalytic oxidation processes for odour and VOC control. Stud. Environ. Sci. 1994;61; 459-467.

2. Volkamer R, Jimenez JL, San Martini F, et al. Secondary organic aerosol formation from anthropogenic air pollution: Rapid and higher than expected. Geophys. Res. Lett. 2006;33:L17811.

3. Zou L, Luo Y, Hooper M, Hu E. Removal of VOCs by photocatalysis process using adsorption enhanced $\mathrm{TiO}_{2}-\mathrm{SiO}_{2}$ catalyst. Chem. Eng. Process. 2006;45:959-964.

4. Li WB, Wang JX, Gong H. Catalytic combustion of VOCs on non-noble metal catalysts. Catal. Today 2009;148:81-87.

5. Mitsuma Y, Ota Y, Hirose T. Performance of thermal swing honeycomb VOC concentrators. J. Chem. Eng. Jpn. 1998;31; 482-484.

6. Mitsuma Y, Yamauchi H, Hirose T. Analysis of VOC reversing adsorption and desorption characteristics for actual efficiency prediction for ceramic honeycomb adsorbent. J. Chem. Eng. Jpn. 1998;31:253-257.

7. Ichiura H, Okamura N, Kitaoka T, Tanaka H. Preparation of zeolite sheet using a papermaking technique. Part II. The strength of zeolite sheet and its hygroscopic characteristics. J. Mater. Sci. 2001;36:4921-4926.

8. Yoo YJ, Kim HS. Adsorption and desorption dynamics of toluene on high silica zeolite honeycomb adsorbent. In: Korean. Soc. Energy Proceedings on Spring Symposium; 2000. p. 307-312.

9. Motsuma Y, Ota Y, Hirose T. Performance of thermal swing honeycomb VOC Concentrators. J. Chem. Eng. Jpn. 1998;31:482-484.

10. Chang FT, Lin YC, Bai H, Pei BS. Adsorption and desorption characteristics of semiconductor volatile organic compounds on the thermal swing honeycomb zeolite concentrator. J. Air Waste Manage. Assoc. 2003;53:1384-1390.

11. Yang J, Chen Y, Cao L, Guo Y, Jia J. Development and field-scale optimization of a honeycomb zeolite rotor concentrator/recuperative oxidizer for the abatement of volatile organic carbons from semiconductor industry. Environ. Sci. Technol. 2012:46: 441-446.

12. Zhao XS, Ma Q, Lu GQ. VOC Removal: Comparison of MCM-41 with hydrophobic zeolites and activated carbon. Energ. Fuel. 1998;12:1051-1054

13. Díaz E, Ordóñez S, Vega A, Coca J. Adsorption characterization of different volatile organic compounds over alumina, zeolites and activated carbon using inverse gas chromatography. J. Chromatogr. A 2004;1049:139-146.

14. Takeuchi Y, Iwamoto H, Miyata N, Asano S, Harada M. Adsorption of 1-butanol and $p$-xylene vapor and their mixtures with high silica zeolites. Sep. Technol. 1995;5:23-34.

15. Lee SW, Kam SK, Lee MG. Comparison of breakthrough characteristics for binary vapors composed of acetone and toluene based on adsorption intensity in activated carbon fixed-bed reactor. J. Ind. Eng. Chem. 2007;13:911-916.

16. Monneyron P, Manero MH, Foussard JN. Measurement and modeling of single- and multi-component adsorption equilibria of VOC on high-silica zeolites. Environ. Sci. Technol. 2003;37:2410-2414

17. Chuang CL, Chiang PC, Chang EE. Modeling VOCs adsorption onto activated carbon. Chemosphere 2003;53:17-27.

18. Bouhamra WA, Elkilani AS, Baker CGJ. Testing adsorbents capacities for indoor volatile organic compounds at optimum operating conditions. WIT Trans. Ecol. Environ. 2006;86:411-420.

19. Yang RT. Gas separation by adsorption processes. Boston: Butterworth; 1987. p. 1-48.

20. Brunaure S, Emmett PH. The use of low temperature van def waals adsorption isotherms in determining the surface areas of various adsorbents. J. Am. Chem. Soc. 1937;59:2682-2689.

21. Cho MW, An D, Yim B, et al. Toluene adsorption characteristics of zeolite depending on temperature and relative humidity. Odor Indoor Environ. 2016;15:368-374. 